"Modeling jumps in organization of petroleum exporting countries basket price using generalized autoregressive heteroscedasticity and conditional jump"

\begin{tabular}{ll} 
AUTHORS & $\begin{array}{l}\text { Mohsen Bahramgiri } \\
\text { Shahabeddin Gharaati } \\
\text { Iman Dolatabadi }\end{array}$ \\
& $\begin{array}{l}\text { Mohsen Bahramgiri, Shahabeddin Gharaati and Iman Dolatabadi (2016). } \\
\text { Modeling jumps in organization of petroleum exporting countries basket price }\end{array}$ \\
\hline ARTICLE INFO & $\begin{array}{l}\text { using generalized autoregressive heteroscedasticity and conditional jump. } \\
\text { Investment Management and Financial Innovations, 13(4-1), 196-202. }\end{array}$ \\
& doi:10.21511/imfi.13(4-1).2016.05 \\
\hline DOI & http://dx.doi.org/10.21511/imfi.13(4-1).2016.05 \\
\hline RELEASED ON & Thursday, 29 December 2016 \\
\hline JOURNAL & "Investment Management and Financial Innovations" \\
\hline FOUNDER & LLC “Consulting Publishing Company "Business Perspectives"
\end{tabular}

NUMBER OF REFERENCES

0

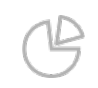

NUMBER OF FIGURES

0

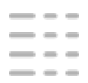

NUMBER OF TABLES

0

(C) The author(s) 2021. This publication is an open access article. 
Mohsen Bahramgiri (Iran), Shahabeddin Gharaati (Iran), Iman Dolatabadi

\title{
Modeling jumps in organization of petroleum exporting countries basket price using generalized autoregressive heteroscedasticity and conditional jump
}

\begin{abstract}
This paper uses autoregressive jump intensity (ARJI) model to show that the oil price has both GARCH and conditional jump component. In fact, the distribution of oil prices is not normal, and oil price returns have conditional heteroskedasticity. Here the authors compare constant jump intensity with the dynamic jump intensity and evidences demonstrate that oil price returns have dynamic jump intensity. Therefore, there is strong evidence of time varying jump intensity Generalized Autoregressive Heteroscedasticity (GARCH) behavior in the oil price returns. The findings have several implications: first, it shows that oil price is highly sensitive to news, and it does settle around a trend in long-run. Second, the model separates variances of high volatilities from smooth volatilities. Third, the model rejects an optimal path for extracting oil and technology transmission. In fact, the lack of a long-term pattern can cause excessive oil extracting which can result in heavy climatic effects.
\end{abstract}

Keywords: generalized autoregressive heteroscedasticity (GARCH), jumps, basket, oil price, Organization of Petroleum Exporting Countries (OPEC), Autoregre-ssive jump intensity (ARJI).

JEL Classification: C32, C52, F31.

\section{Introduction}

The subject of oil price includes an extensive literature consisting of both theoretical and practical researches. There are three primary methods for describing oil price behavior in the literature: first, Hotelling (1931) theory which indicates that oil is an infinite source and its price follows a long-term increasing pattern. There are different extensions of this primary model. Second, researches that likes of Krichen (2002) and Dees et al. (2007) who tried to describe oil price in the context of demand and supply in macroeconomics. The third method includes Dees et al. (2007), Kaufmann and Ulman (2009), which followed the subject in a more unorthodox way and focused on OPEC power and the role of speculation. The other important branch of the literature addresses the question that whether there is a permanent and systematic pattern for the price of exhaustible resources in the present time. Results obtained in this relation are not clear, but Slade (1998) does find practical evidence that the pattern is random; Slade (1982) and Lee et al. (2006) conclude that there is a second order, a permanent pattern with structural break, as it was expected. Finally, Pindyck (1999) concluded that the real price of oil fluctuates around a long-term pattern and the pattern itself is random. Previous models show that daily data on oil price and complex practical techniques are heavily used. Notwithstanding the fact that techniques such as GARCH models, artificial neural networks and jump-diffusion processes have

(C) Mohsen Bahramgiri, Shahabeddin Gharaati, Iman Dolatabadi, 2016. Mohsen Bahramgiri, Assistant Professor, School of Management and Economics, Sharif University of Technology, Tehran, Iran. Shahabeddin Gharaati, Sharif University of Technology, Tehran, Iran. Iman Dolatabadi, Sharif University of Technology, Tehran, Iran. been used, oil price behavior shows peculiar signals. In fact, change in true oil price historically tends to be permanent, difficult to predict, and led by very different regimes in different times.

In this paper, autoregressive jump intensity (ARJI) model is used for modeling volatility of oil price return. This paper shows that many oil price behaviors are the same as the stock market behavior, since one can use models, which are used for modeling volatility of stock return, to model volatility of oil price return. In the second section, we introduce the ARJI model. In addition, descriptive statistics and data analysis are presented in third section. Section four discusses empirical results, and finally in the last section, the implication is mentioned.

\section{Literature review}

Oil price has attracted significant attention from financial econometrics scholars. Many scientific studies address issues like volatility of oil price (Foster, 1995; Pindyck, 2004; Jebabli et al., 2014), and hedging (Lien et al., 2002). Ji and Guo (2015) analyzed the impacts effects of four types of oil-related events on world oil prices, using AR-GARCH model. Their results indicate that effect of the global financial crisis on oil price returns is negatively significant, while the effect of the Libyan war and hurricanes is positively significant. Diaz et al. (2016) investigated the relationship between oil price volatility and stock returns in the G7 economies in the period 1970 to 2014 for monthly data. Results show that there is a negative response of G7 economies' stock markets to an increase in oil price volatility. Outcomes also show that volatility of world oil price is usually more significant for G7 economies' stock markets than the national oil price volatility. Loren- 
zo et al. (2016) used the Clayton and Gumbel copulas using the TGARCH model to investigate the tail dependence between oil prices and the Mexican stock market index on a weekly basis, from 2010 to 2014. Agri et al. (2016) investigated the effect of oil price volatility on macroeconomic variables and sustainable development in Nigeria using secondary time series data in a vector auto regression analysis. Results show that variations in oil prices considerably affect the real GDP, exchange rates, unemployment, balance of payments and interest rates in Nigeria.

Many studies have focused on oil price predictions (Morana, 2006; Moshiri and Forootan, 2006; Baumeister\&Kilian, 2014). Klein and Walther (2015) compared Mixture Memory GARCH (MMGARCH) modelto other discrete volatility models $(\mathrm{GARCH}$, FIGARCH, and HYGARCH) for volatility and Value-at-Risk forecasting of oil price returns. They indicated that MMGARCH outperforms the other discrete volatility modelsbecause of its dynamic nature in varying the volatility level and memory of the process. Mostafa and El-Masry (2016) used gene expression programming and artificial neural network (ANN) models to predict oil prices over the period of 1986 to 2012. The results show that the GEP outperforms ANN and ARIMA models in predicting oil prices. Baumeister and Kilian (2015) appliedsix real-time econometric oil price forecasting modelscombinations. They proposed that appropriately forecast models combinations should replace traditional judgmental forecasts of the price of oil such as the U.S. Energy Information Administration (EIA). Some related works are Askari and Krichene (2008) and Agnolucci (2009).

\section{Methodology}

2.1. Autoregressive jump intensity model for oil volatility. The aim of this study is modeling the oil price volatility. One of the features of crude oil markets is very intense volatility and, in some cases, such as during the Gulf war, jump in the time series data associated to crude oil. In this study, ARJI model proposed by Chan and Maheu (2002) is used for measuring the volatility of crude oil.Assume that the information set of data at time $t-1$ is $\Omega_{t}=$ $\left\{r_{1}, \ldots, r_{t-1}\right\}$ and two shocks $\varepsilon_{1, t}$ and $\varepsilon_{2, t}$ have happened. A jump model is presented as follows:

$R_{t}=\mu+\sum_{i=1}^{2} \phi_{i} R_{t-i}+\varepsilon_{1, t}+\varepsilon_{2, t}$

In this equation, $R_{t}$ is growth rate of oil price which is calculated byln $\left(\frac{p_{t}}{P_{t-1}}\right)$ and $P_{t}$ is oil price at time;

furthermore, $\varepsilon_{1, t}$ is a normal stochastic process and it is assumed that:

$\varepsilon_{1, t}=\sqrt{h_{t}} Z_{t} Z_{t}=N I D(0,1)(2)$
Let smooth conditional variance $h_{t}$ be a $\operatorname{GARCH}(1,1)$ process. We can write:

$$
\begin{aligned}
h_{t}=\omega+\alpha \varepsilon_{t-1}^{2} & +\beta h_{t-1} \varepsilon_{t-1} \\
& =\varepsilon_{1, t-1}+\varepsilon_{2, t-1}
\end{aligned}
$$

On the other hand, $\varepsilon_{2, t}$ is the shock associated with jump which its conditional expectation is zero and

$$
\begin{aligned}
\varepsilon_{2, t}=J_{t}-E\left[J_{t} \mid \Omega_{t-1}\right] & \\
& =\sum_{k=1}^{n_{t}} \pi_{t, k}-\theta \lambda_{t}
\end{aligned}
$$

Where $J_{t}$ is a variable that affects stock return in $(t-1, t)$ interval and equals $\sum_{k=1}^{n_{t}} \pi_{t, k}$. It'sassumed that the jump size $\pi_{t, k}$ comes from a normal distribution with average $\theta_{t}$, and variance $\delta_{t}^{2} \cdot n_{t}$ is a variable that represents a separate counting process that records the number of jumps in $(t-1, t)$ and follows a Poisson distribution with parameter $\lambda_{t}>0$. The probability density function is:

$P\left(n_{t} \mid \Omega_{\mathrm{t}-1}\right)=e^{-\lambda_{t}} \lambda_{t}^{j} j$ !

Both the average and variance of the random variable is $\lambda_{t}$ which is called jump intensity and is assumed to be an autoregressive process with the following moving average:

$\lambda_{t}=\lambda_{0}+\rho \lambda_{t-1}+\gamma \xi_{t-1}(6)$

Where $\xi_{t-1}$ is the shock for $\lambda_{t-1}$ and is aimed to measure the unexpected jumps at $n_{t-1}$ and updating the existing information set:

$$
\begin{aligned}
\xi_{t-1} \equiv E\left[n_{t-1} \mid \Omega_{t-1}\right]- & \\
& =\left[\sum _ { j = 0 } ^ { \infty } j P \left(n_{t-1}\right.\right. \\
& \left.\left.=j \mid \Omega_{t-1}\right)\right]-\lambda_{t-1}
\end{aligned}
$$

$P\left(n_{t-1}=j \mid \Omega_{t-1}\right)$ is calledfilter and according to the given informational set $\Omega_{t-1}$ and $E\left[n_{t-1} \mid \Omega_{t-1}\right]$ that identifies expected number of jumps in $(t-2, t-$ 1) interval, extracts $n_{t-1}$. Note that according to definition $\xi_{t}$ is a martingale difference sequence with respect to the information in $\Omega_{t-1}$; therefore $E\left[\xi_{t}\right]=$ 0 and $\operatorname{cov}\left(\xi_{t-i}, \xi_{t}\right)=0, i>0$ and we can write jump intensity as:

$$
\lambda_{t}=\lambda_{0}+(\rho-\gamma) \lambda_{t-1}+\gamma E\left[n_{t-1} \mid \Omega_{t-1}\right]
$$

where and $\lambda_{0}>0, \rho \geq \gamma, \gamma \geq$

The conditional variance of return is consisted of two parts; one part represents smooth conditional variance and is affected by past news. The other parts is conditional variance of arrival heterogeneous information which creates a jump. the conditional variance of returns is:

$$
\begin{aligned}
& \operatorname{Var}\left(R_{t} \backslash \Omega_{t-1}\right)=\operatorname{Var}\left(\epsilon_{1, t} / \Omega_{t-1}\right)+ \\
& +\operatorname{Var}\left(\epsilon_{2, t-1} / \Omega_{t-1}\right)=h_{t}+\left(\theta_{t}^{2}+\delta_{t}^{2}\right) \lambda_{t}
\end{aligned}
$$


Now we make the likelihood function such that jth jump happens and conditional density of return be normal. We have:

$f\left(R_{t} \backslash n_{t}=j, \Omega_{t-j}\right)=\sqrt{2 \pi\left(h_{t}+j \delta_{t}^{2}\right.} \times \exp \left[-\left(R_{t}-\mu-\sum_{i=1}^{2} \varphi_{i} R_{t-i}+\theta_{t} \lambda_{t}-j \theta_{t}\right)^{2} 2\left(h_{t}+j \delta_{t}^{2}\right]\right.$

Chan and Maheu (2002) proposed a distribution for the number of jumps:

$$
\begin{aligned}
& P\left(n_{t}=j \backslash \Omega_{t}\right)=f\left(R_{t} \backslash n_{t}=j, \Omega_{t-1}\right), \\
& P\left(n_{t}=j \backslash \Omega_{t-1}\right) P\left(R_{t} \backslash \Omega_{t-1}\right) \quad j=0,1,2, \ldots
\end{aligned}
$$

When we calculate the sum of all possible jumps, the conditional probability density function is stated $f\left(R_{t} \mid \Omega_{t-1}\right)=$

$$
=\sum_{j=0}^{\infty} f\left(R_{t} \mid n_{t}=j, \Omega_{t-1}\right) P\left(n_{t}=j \mid \Omega_{t-1}\right)
$$

Therefore we can write the likelihood function:

$L(\psi)=\sum_{j=0}^{\infty} \log f\left(R_{t} \mid \Omega_{t-1} ; \psi\right)$

where $\psi\left(\mu, \phi_{1}, \phi_{2}, \omega, \alpha, \beta, \lambda_{0}, \rho, \gamma\right)$ is the parameters vector to be estimated.

\section{Data analysis}

The data of this study are daily OPEC basket prices

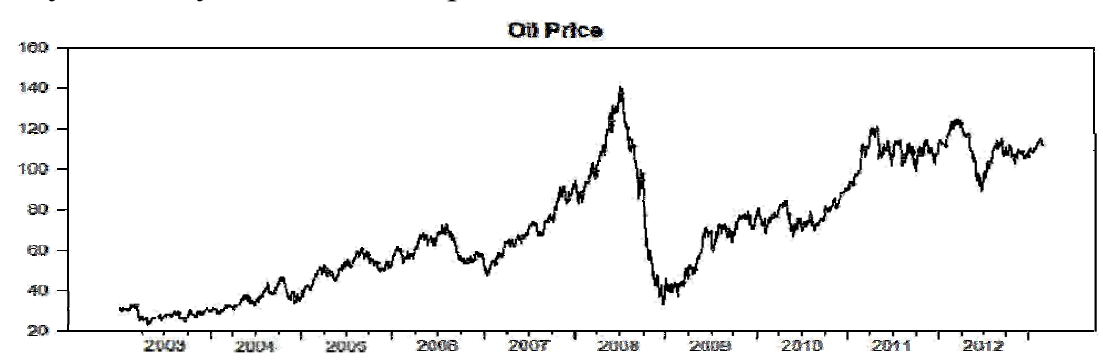

Fig 1. Oil price from January 22003

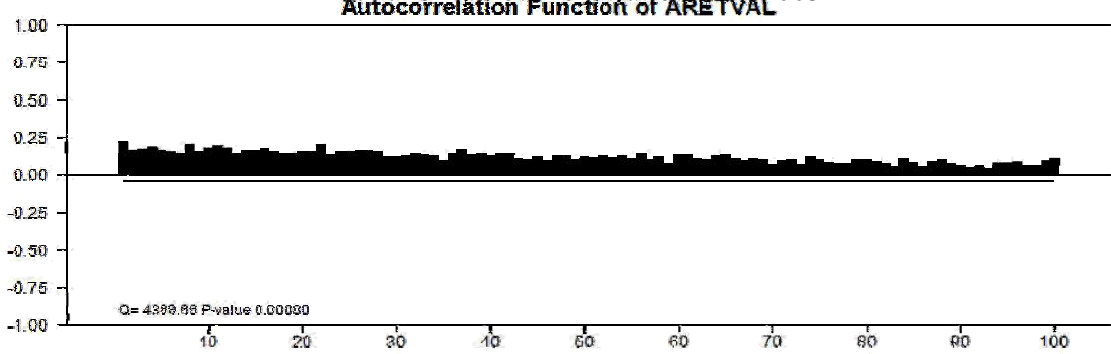

Fig. 2. Oil return from January 2, 2003

Kernel density diagram verifies the obtained result that oil price return is not normal. As you can see in figure 5, while right tail in normal distribution is thicker than right tail in kernel density distribution, the latter has a thicker left tail.

Table 1 shows initial statistics of oil price and oil price growth. We can see that the skewness of oil
(USD per barrel) from January 2, 2003 to February 23,2012 . The time series of oil price is shown in Figure 1. The main variable used in modeling oilvolatility is oil price return and is calculated from $\ln \left(p_{t} / p_{t-1}\right)$. Figure 2 shows oil price returns. Asit can be seen, there's a period of calm oil volatility followed by a period of intense oil volatility, and there's a calm period after that intense period. Hence, clustering oil volatility periods are very similar to clustering stock market volatility periods, and in general, financial variables. But the similarity between oil price return and financial market variables such as stock return is not limited to clustering. Figure 3 depicts the auto-relation function of absolute value oil price return. Slow and gradual decrease of the auto-relation function represents the long-term memory of oil price return variable. Also in figure 4, comparison between practical quintiles of oil price return and normal distribution quintiles obviously shows that the normal distribution assumption for oil price change does not hold. 


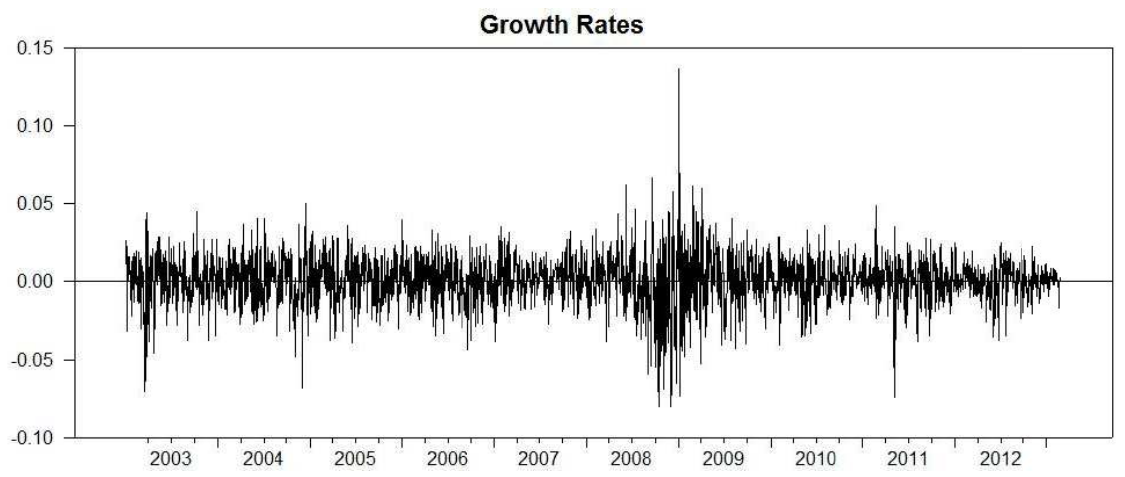

Fig. 3: Auto correlation function of absolute oil return

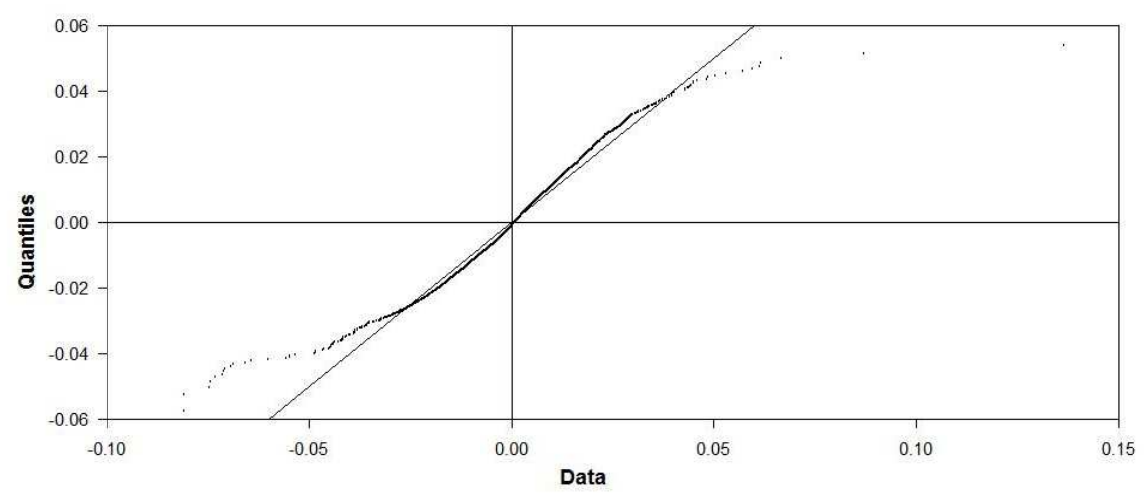

Fig. 4. Q-Q diagram of oil return in comparison with normal distribution

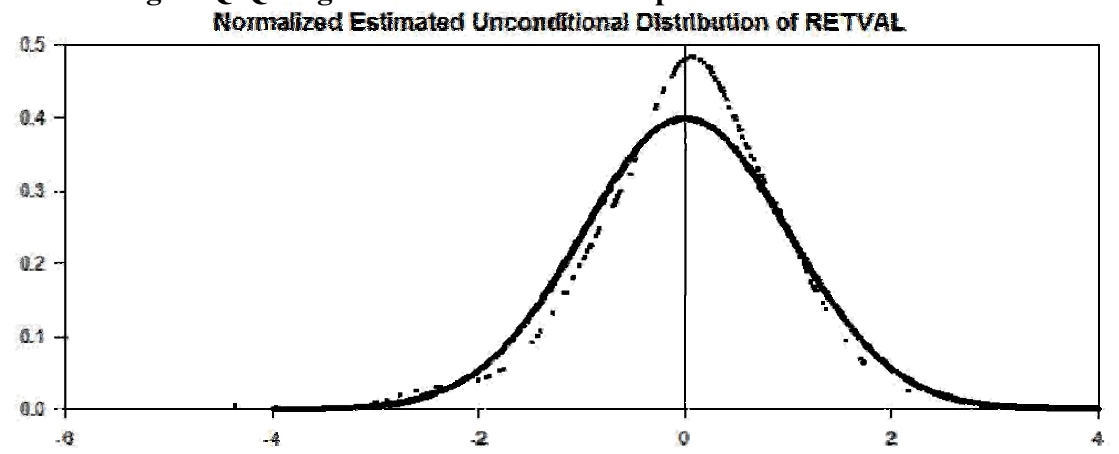

Fig. 5. Kernel density diagram of oil price

Table 1. Descriptive statistics of oil prices returns. OBS stands for observations and JB stands for Jarque-Bra statistic, and S.D stands for standard deviation. Numbers in parenthesis are meaningfulness level.

\begin{tabular}{|l|c|c|c|c|c|c|c|c|}
\hline & Obs & Mean & S.D & Max & Min & Skewness & Kurtosis & JB \\
\hline Oil Price & 2386 & 65.785 & 27.418168 & 140.73 & 23.27 & 0.459372 & $0.647201-$ & 125.559337 \\
\hline & & & & & & $(0.00)$ & $(0.00)$ & $(0.00)$ \\
\hline Return & 2385 & 0.000730 & 0.016925 & 0.1365935919 & -0.0808661069 & -0.232827 & 3.757002 & 1424.231900 \\
\hline & & & & & & $(0.00)$ & $(0.00)$ & $(0.00)$ \\
\hline
\end{tabular}

\section{Empirical Results}

Table 2 is the results of estimation of model in both constant jump intensity and variable jump intensity (ARJI). It shows that all coefficients except $\omega$ are significant both models and is only significant at 10 percent level in ARJI model. With the value of 0.78 suggests high linear correlation between jump variables and this is one of the reasons of jump variability in time. Besides, linear correlation in average equation is completely vanished when introducing last period and two last periods, and both coefficients in both models are highly meaningful. At last, LB statistic rejects linear and non-linear correlation up to 15 periods. In addition to using LB statistic for the entire model, it is also used for testing correlation of jump variables. In constant jump model, testing shows that linear correlation of jump shocks exist and this linear correlation rejected in ARJI model. Hence, jump being constant 
with respect to time is rejected in the first model.

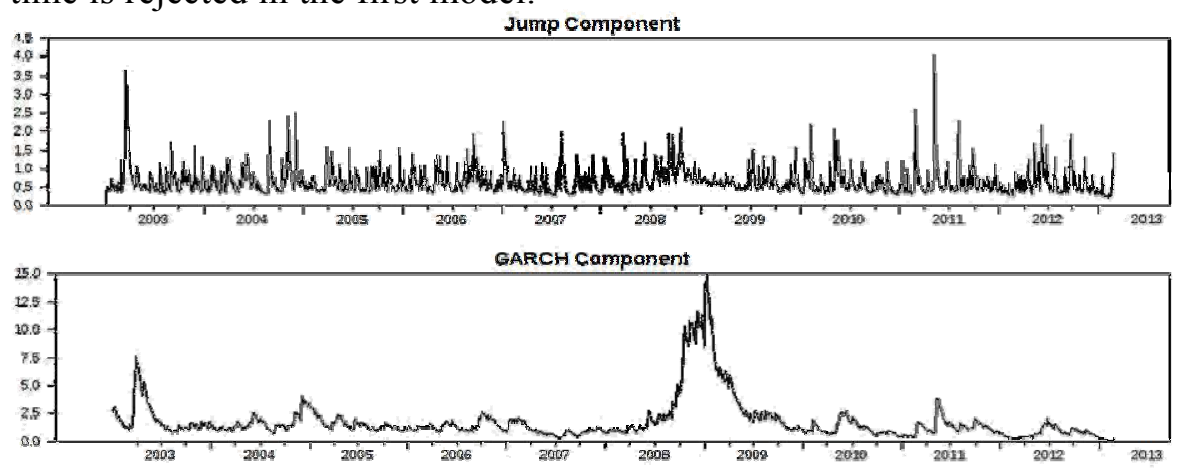

Fig. 6: conditional variance components of oil return

In 2000s, oil market witnessed two remarkable events: first, the oil price increase which had been started in 2003, and second, the dramatic decrease of oil price, which had been started in mid-2008 and had stopped by the end of that year. Figure 7 shows these two events more accurately by using price returns and conditional variance of jump intensity. In March 2003 we can see a significant drop in prices and increase in oil returns volatility at the same time. Jump variance is largely increased in this period and reaches over 1.25 from 0.25 . We also have large increase and decrease of oil price and oil price re- turns volatility in August and October and November, and we can see that in these periods, conditional variance of jump is increased considerably. In the early 2008 we can see a slow and smooth increase in oil price followed by a significant decrease in June 2008. In most cases, this decrease is made of several partial price decreases and both jump variable and conditional variance of jump react to this when this decrease is intense. In fact, in every period, jump variable is slowly increased to a considerable value which means that jumps seldom happen. This is an answer for long-term memory of oil returns data set.
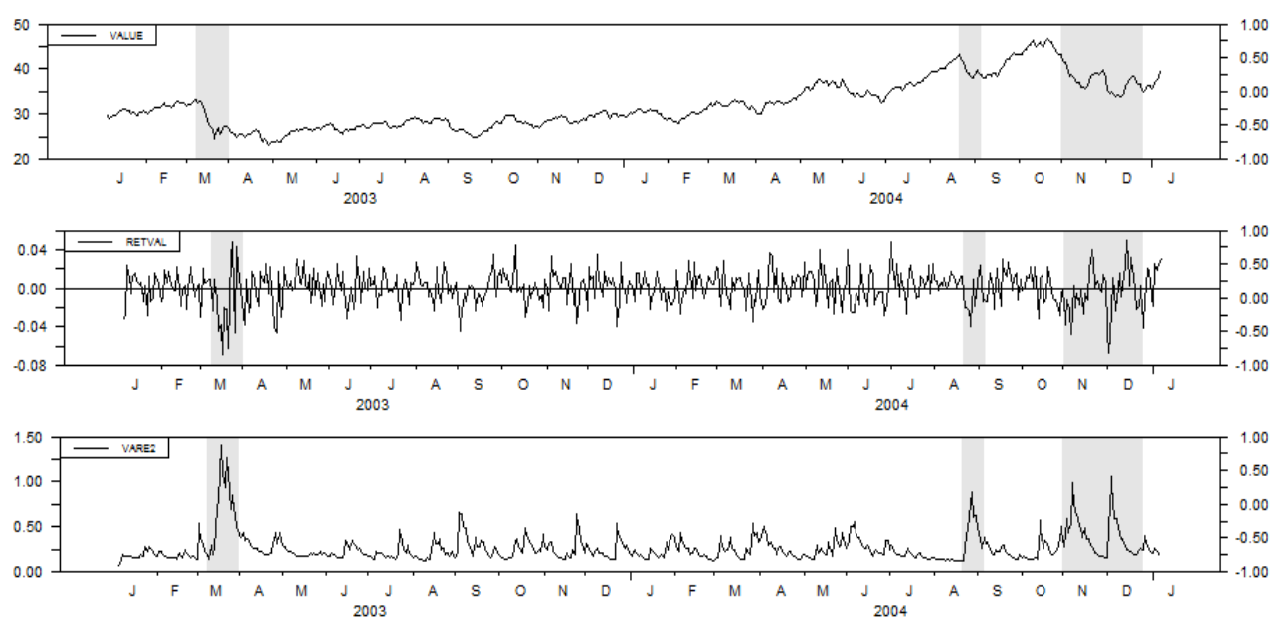

Fig. 7. Oil price, oil price return, jump conditional variance

Table 2. Practical results of ARJI model for crude oil volatility

\begin{tabular}{|l|c|c|}
\hline \multicolumn{1}{|c|}{ Parameter } & Constant & ARJI \\
\hline$\mu$ & 0.221584785 & 276296084 \\
\hline & $(0.00)$ & $(0.00)$ \\
\hline$\varphi_{1}$ & 0.257002610 & 0.229105601 \\
\hline & $(0.00)$ & $(0.00)$ \\
\hline$\varphi_{2}$ & -0.066117141 & -0.086183394 \\
\hline & $(0.00)$ & $(0.00)$ \\
\hline$\omega$ & 0.000884924 & -0.001755562 \\
\hline & Constant & ARJI \\
\hline & $(0.85)$ & $(0.65)$ \\
\hline a & 0.055913242 & 0.037703569 \\
\hline
\end{tabular}

\begin{tabular}{|l|c|c|}
\hline & $(0.00)$ & $(0.00)$ \\
\hline$\beta$ & 0.928890890 & 0.947870281 \\
\hline & $(0.00)$ & $(0.0) 0$ \\
\hline$\lambda_{0}$ & 0.306281347 & 0.139156893 \\
\hline & $(0.03)$ & $(0.09)$ \\
\hline$\rho$ & & 0.784354962 \\
\hline & & $(0.00)$ \\
\hline$Y$ & & 0.861232316 \\
\hline & & $(0.00)$ \\
\hline & 20.09 & 18.64 \\
\hline$Q^{2}$ & $(0.16)$ & $(0.23)$ \\
\hline & 14.50 & 12.23 \\
\hline$Q_{s t}$ & $(0.48)$ & $(0.66)$ \\
\hline
\end{tabular}




\begin{tabular}{|l|c|c|}
\hline & $(0.00)$ & $(0.15)$ \\
\hline Log-likelihood & -4665.8019 & -4652.7922 \\
\hline
\end{tabular}

$R_{t}=\mu+\sum_{i=1}^{2} \phi_{i} R_{t-i}+\varepsilon_{1, t}+\varepsilon_{2, t}(14)$

$\varepsilon_{1, t}=\sqrt{h_{t}} Z_{t}, Z_{t}=N I D(0,1), h_{t}=\omega+$

$+\alpha \varepsilon_{t-1}^{2}+\beta h_{t-1}, \quad \varepsilon_{t-1}=\varepsilon_{1, t-1}+(15)$

\section{Conclusion}

In this paper, we used the model of Chan and Maheu (2002) which was previously used to model stock return and exchange rate, to model OPEC oil price change. Two reasons supported this approach. First, there was evidence on similarities between oil data and stock market data and there was a possibility of using the models associated to stock market data in oil data analysis. Second, the above model could be effective in modeling unexpected events and news such as sudden increase in prices. In addition, low price elasticity of oil demand and supply and simultaneous large change in prices for clearing even small excess supply or demand was another motive for using such a model; but the thing that makes the Chan and Maheu (2002) model more interesting than other jump models, was the dynamic nature of jump variable and change of its magnitude and frequency over time. In fact, in other models, the jump variable was constant and this was a limiting assumption. Second, in contrast with most of the financial econometrics models that focus on techniques rather than results, findings of this model were associated to some theoretical findings of particular importance.

Hotelling (1931) stated a famous law on oil price; price of a finite resource in the optimal settings rises with interest rate. Later, the Hotelling theory was developed by considering global warming and greenhouse gas emissions. The result of this development was that ignoring greenhouse gas emissions can result in excessive oil extracting. Furthermore, the information extracted from oil price is crucial for technology change decisions and oil price is a better indicator of the lack of resources than the amount of oil production. Using the Chan and Maheu (2002) model showed strong evidence on GARCH model behaviors and also conditional jump intensity in daily data of oil price; that is, conditional heteroscedasticity variance exists and practical distribution has fat tail. Furthermore, this model has high sensitivity to events and news and, therefore, it does not fluctuate around a long-term pattern; and despite that previous theories hold that prices fluctuate around an increasing pattern and oil price contains information, this model rejects the existence of such information. The most important result of this model is the rejection of an optimal path for extracting oil and technology transmission. In fact, the lack of a long-term pattern can cause excessive oil extracting which can result in heavy climatic effects.

\section{References}

1. Agnolucci, P. (2009). Volatility in Crude Oil Futures: A Comparison of the Predictive Ability of GARCH and Implied Volatility Models, Energy Economics, 31, pp. 316-321.

2. Agri, E.M., Inusa, M.L.D. and Kennedy, N. D. (2016). Impact of Oil Price Volatility on Macroeconomic Variables and Sustainable Development in Nigeria, International Journal of Economics and Financial Research, 2(2), pp. 33-40.

3. Askari, H. and Krichene, N. (2008). Oil Price Dynamics (2002-2006), Energy Economics, 30 , pp. 2134-2153.

4. Baumeister, C. and Kilian, L. (2014). Real-time Analysis of Oil Price Risks Using Forecast Scenarios, IMF Economic Review, 62(1), pp. 119-145.

5. Baumeister, C. and Kilian, L. (2015). Forecasting the Real Price of Oil in a Changing World: a Forecast Combination Approach, Journal of Business and Economic Statistics, 33(3), pp. 338-351.

6. Chan, W. and Maheu, J. (2002). Conditional Jump Dynamics in Stock Market Returns, Journal of Business Economic Statistics, 20 , pp. 377-389.

7. Dees, S., Karadeloglou, P., Kaufmann, R. and Sanchez, M. (2007). Modelling the World Oil Market: Assessment of a Quarterly Econometric Model, Energy Policy, 35 , pp. 178-191.

8. Diaz, E.M., Molero, J.C. and de Gracia, F.P. (2016). Oil Price Volatility and Stock Returns in the G7 Economies,Energy Economics, 54, pp. 417-430.

9. Foste, A. (1995). Volume-Volatility Relationships for Crude Oil Futures Markets. The Journal of Futures Markets, 15 , pp. $929-951$.

10. Hotelling, H. (1931). The Economics of Exhaustible Resources. The Journal of Political Economy, 39,pp. 137-175.

11. Jebabli, I., Arouri, M. and Teulon, F. (2014). On the Effects of World Stock Market and Oil Price Shocks on Food Prices: An Empirical Investigation Based on TVP-VAR Models with Stochastic Volatility, Energy Economics, 45, pp. 66-98.

12. Ji, Q. and Guo, J.F. (2015). Oil Price Volatility and Oil-Related Events: An Internet Concern Study Perspective, Applied Energy, 137, pp. 256-264.

13. Kaufmann, R. and Ullmann, B. (2009). Oil Prices, Speculation and Fundamentals: Interpreting Causal Relations among Spot and Futures Prices, Energy Economics.

14. Klein, T. and Walther, T. (2016). Oil Price Volatility Forecast with Mixture Memory GARCH, Available at SSRN 2576875 . 
15. Krichene, N. (2002). World Crude Oil and Natural Gas: a Demand and Supply Model, Energy Economics, 24, pp. 557-576.

16. Lee, J., List, J. and Strazicich, M. (2006). Non-Renewable Resource Prices: Deterministic or Stochastic Trends? Journal of Environmental Economics and Management 51, pp. 354-370.

17. Lien, D., Tse, Y. and Tsui, A. (2002). Evaluating the Hedging Performance of the Constant-Correlation GARCH Model, Applied Financial Economics, 12, 791798.

18. Lorenzo, A., Fraire, L.A. and Vázquez, R.D. (2016). A Copula-TGARCH Approach of Conditional DependenceBetween Oil Price and Stock Market Index: the Case of Mexico, Estudios económicos, 31(1), pp. 47-63.

19. Moshiri, S. and Foroutan, F. (2006). Forecasting Nonlinear Crude Oil Future Prices. The Energy Journal, 27, pp. 81-95.

20. Mostafa, M.M. and El-Masry, A.A. (2016). Oil Price Forecasting Using Gene Expression Programming and Artificial Neural Networks, Economic Modelling, 54, pp. 40-53.

21. Pindyck, R. (1979). Some Long-term Problems in OPEC Oil Pricing, Journal of Energy and Development, 4(2), pp. 259-272.

22. Pindyck, R. (1999). The Long-Run Evolution of Oil Prices, The Energy Journal,20 , pp. 1-26.

23. Pindyck, R. (2004a). Volatility in Natural Gas and Oil Markets, Journal of Energy and Development, 30, pp. 1-21.

24. Pindyck, R. (2004b). Volatility and Commodity Price Dynamcis, The Journal of Futures Markets, 24, pp. $1029-1047$.

25. Slade, M. (1982). Trends in Natural-Resource Commodity Prices: An Analysis of the Time Domain, Journal of Environmental Economics and Management, 9, pp. 122-137.

26. Slade, M. (1988). Grade Selection under Uncertainty: Least Cost Last and other Anomalies, Journal of Environmental Economics and Management,15, pp. 189-205. 